\section{Case Report}

\section{*Corresponding author \\ Naruki Higashidate, MD}

Department of Pediatric Surgery

Niigata City General Hospital

463-7 Shumoku, Chuou-ku

Niigata City, Niigata 950-1197, Japan

Tel. +81-25-281-5151

Fax: +81-25-281-5187

E-mail: higashidate_naruki@med.kurume-u.ac.jp

Volume 3 : Issue 2

Article Ref. \#: 1000EMOJ3142

\section{Article History}

Received: December $7^{\text {th }}, 2017$

Accepted: December 9 $9^{\text {th }}, 2017$

Published: December $11^{\text {th }}, 2017$

\section{Citation}

Higashidate N, linuma $\mathrm{Y}$, Hirayama $\mathrm{Y}$, lida $\mathrm{H}$, Komatsuzaki $\mathrm{N}$. Obstruction of small bowel caused by unconscious trichotillomania: Rapunzel syndrome. Emerg Med Open J. 2017; 3(2): 54-57. doi: 10.17140/EMOJ-3-142

\section{Copyright}

(C)2017 Higashidate N. This is an open access article distributed under the Creative Commons Attribution 4.0 International License (CC BY 4.0), which permits unrestricted use, distribution, and reproduction in any medium, provided the original work is properly cited.

\title{
Obstruction of Small Bowel Caused by Unconscious Trichotillomania: Rapunzel Syndrome
} Naruki Higashidate, MD*; Yasushi linuma,MD, PhD; Yutaka Hirayama, MD, PhD;
Hisataka lida, MD; Naoko Komatsuzaki, MD

Department of Pediatric Surgery, Niigata City General Hospital, 463-7 Shumoku, Chuou-ku, Niigata City, Niigata 950-1197, Japan

\section{ABSTRACT}

Rapunzel syndrome is a relatively rare condition in which swallowed hair masses extend to a point distal to the pylorus and cause intestinal problems. Although trichotillomania and trichophagia are secondary to psychiatric illnesses, these conditions tend to be concealed by caregivers in most pediatric cases. Rapunzel syndrome sometimes manifests as acute abdominal symptoms of unknown origin and is difficult to manage appropriately. A 14-year-old female patient was referred to our hospital due to a small bowel obstruction. Although her medical history of trichotillomania was hidden at presentation, a definitive diagnosis of Rapunzel syndrome was made based on the findings from contrast-enhanced computed tomography (CECT). The patient underwent exploratory laparotomy, and hairballs were removed via an incision of the gastric and intestinal walls. The patient recovered uneventfully and was discharged on the $11^{\text {th }}$ post-operative day. Periodical psychiatric counseling is ongoing in order to prevent recurrence. Pediatric trichotillomania often progresses unconsciously, and appropriate care is necessary to prevent the development of a potentially fatal condition like Rapunzel syndrome. CECT is useful for making a definitive diagnosis of Rapunzel syndrome and determining the surgical approach. Radical laparotomy is considered to be reasonable and feasible in cases of Rapunzel syndrome, which manifests as acute abdominal symptoms.

KEY WORDS: Trichotillomania; Trichophagia; Trichobezoar; Rapunzel syndrome.

\section{INTRODUCTION}

Rapunzel syndrome is caused by the accumulation of a large amount of trichobezoar that extends distally to the pylorus to the duodenum or small intestine. The large trichobezoar is the result of long-term trichotillomania and trichophagia due to underlying psychological problems. Rapunzel syndrome sometimes manifests as acute abdominal symptoms such as small bowel obstruction, intussusception or perforation; therefore, urgent and appropriate management is required. In addition to making a definitive diagnosis, the detection of the location of the masses is necessary for complete removal. Recently, endoscopic and laparoscopic approaches, which have good cosmetic outcomes, has been introduced for the treatment of trichobezoars. However, in Rapunzel syndrome, these approaches are considered to be indicated in only limited cases. In most pediatric patients, trichotillomania and trichophagia persist unconsciously, and these conditions are underestimated and concealed by caregivers. Appropriate psychiatric care is necessary for further prevention after acute-phase treatment.

In this report, we describe a 14-year-old female with this syndrome, with a focus on the characteristic findings of a radiological examination and the surgical approach.

\section{CASE REPORT}

A 14-year-old female patient with a 5-day history of epigastric pain and postprandial vomiting was admitted to our institution. Although, she had no remarkable gastrointestinal history, a 
physical examination revealed distention and tenderness in the upper abdominal region. The possibility of mild intestinal obstruction of unknown origin was raised. At the time of the first clinical interview, neither the patient nor her parents mentioned any remarkable medical history and insisted that she had lived a normal life.

CECT revealed the presence of huge oval masses ranging from 6 to $16 \mathrm{~cm}$ in diameter in the stomach, duodenum, and dilated proximal jejunum (Figure 1A and 1B). Wall thickening was shown from the stomach to the proximal jejunum. All of the masses contained a large amount of air and showed similar structures on the radiological findings. The point of intestinal obstruction was easily identified at the proximal jejunum. These findings suggested that the small bowel obstruction in this patient had been caused by some swallowed materials. In addition, given the characteristic structures on the radiological findings, trichobezoars were strongly suspected to be responsible for the intestinal obstruction, and a definitive diagnosis of Rapunzel syndrome was made.

Based on this diagnosis, we tried to confirm any prior episodes of swallowing foreign bodies; however, the patient and her parents strongly denied episodes of trichotillomania or trichophagia. The patient underwent exploratory laparotomy in which the accumulation of a moderate amount of serous ascites and dilatation of the proximal jejunum were revealed. The point of jejunal obstruction was $30 \mathrm{~cm}$ distal to the ligament of Treitz (Figure 2A). At this point, a hard mass about $6 \mathrm{~cm}$ in diameter was removed after the incision of the jejunum wall (Figure 2B). The mass was a trichobezoar, and all of the trichobezoars in the small bowel were removed via the same incision. Following this procedure, an anterior wall gastrotomy was made, and a large trichobezoar measuring $16 \mathrm{~cm}$ in diameter was removed from the stomach (Figures 2C and 2D). These findings revealed that the patient had apparently continued the trichotillomania unconsciously for a long time. The total weight of the removed trichobezoar was $170 \mathrm{~g}$ (Figure 3).

The post-operative course was uneventful, and a third clinical interview was performed to confirm the patient's history of trichotillomania. Consequently, the parents revealed that the patient had suffered from patchy alopecia, and a diagnosis of trichotillomania had been made when she was 10 years old. However, they had not addressed this condition nor paid particular attention to the whereabouts of the large amounts of pulled hair. In addition, the parents believed that the trichotillomania had subsided after a brief interval, as the patient's hair was long and concealed the patchy alopecia. The patient was discharged on the $11^{\text {th }}$ post-operative day and has resumed her normal activity. The patient has been receiving psychological counseling to prevent the recurrence of further trichotillomania and trichophagia.

\section{DISCUSSION}

Rapunzel syndrome is a severe condition of trichobezoar named after a fairy-tale princess with long hair. This syndrome was first described in 1968 and was initially defined as the presence of a

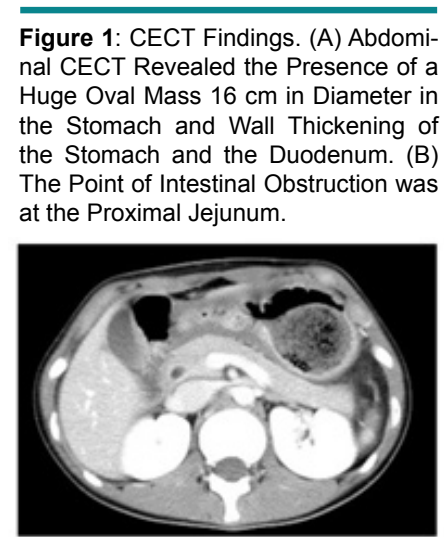

A

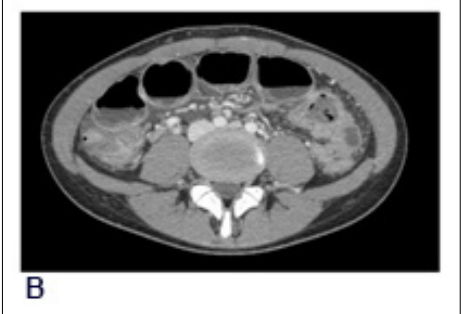

Figure 2: Intraoperative Findings. (A) The Point of Jejunal Obstruction was $30 \mathrm{~cm}$ Distal to the Ligament of Treitz and Contained a Hard Hair Ball. (B) A Hard Mass about $6 \mathrm{~cm}$ in Diameter was Exposed after the Incision of the Jejunum Wall. (C) An Anterior Wall Gastrotomy was Made in Order to Remove the Hair Ball in the Stomach. (D) A Large Trichobezoar $16 \mathrm{~cm}$ in Diameter was Removed from the Stomach.
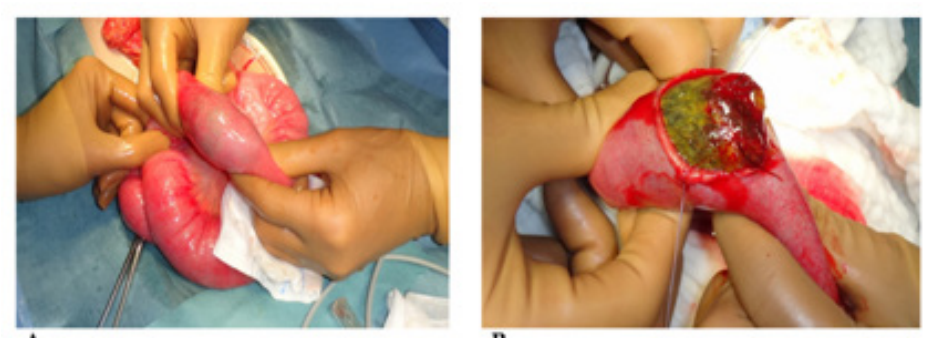

A

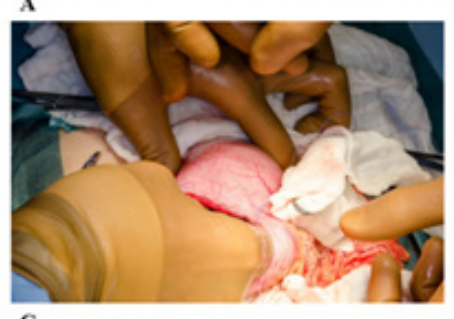

B

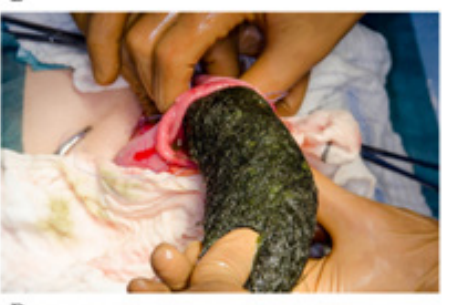




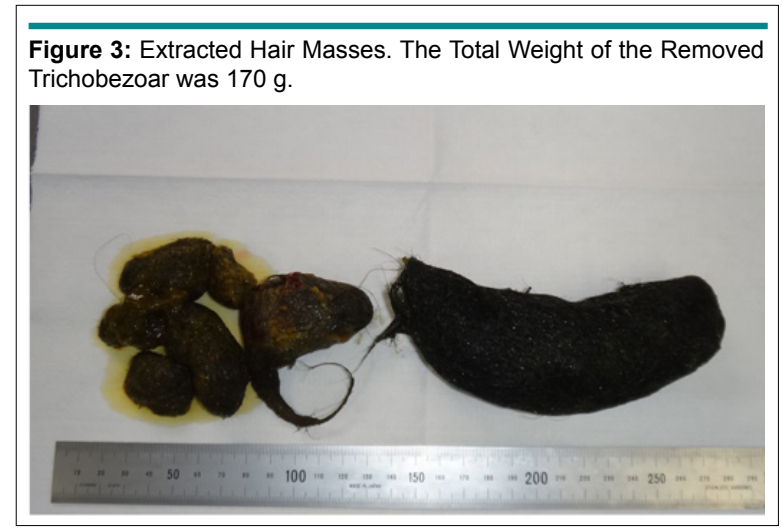

giant trichobezoar with a long tail enough to reach a point distal to the small intestine or colon. ${ }^{1}$ Recently the definition has been expanded to include trichobezoar cases in which the hair mass extends to a point distal to the pylorus, regardless of the continuity of the tail.

Urgent and appropriate management is necessary, as this syndrome sometimes manifests as acute abdominal symptoms such as small bowel obstruction. CECT was reported to be superior to other modalities for detecting bezoars associated with intestinal obstruction. ${ }^{2}$ Bezoars in the small intestine usually present with a mottled gas pattern and a focal ovoid or round intraluminal mass with regular margins and heterogeneous internal structures. Small bowel bezoars are sometimes confused with feces; however, small bowel bezoars can be discriminated in that small bowel feces occupy a relatively long segment of a dilated small intestine. ${ }^{3}$ Although, the patient's history of trichotillomania was unknown at presentation, the definitive diagnosis of Rapunzel syndrome was made solely based on the CECT findings in the present case. The huge oval mass with a large amount of air in the stomach was characteristic of a trichobezoar. In addition, the most significant finding on CECT in the present case was that the gastric and intestinal masses were in the same configuration. This finding suggested that the small bowel obstruction was caused by some indigestible materials. In addition to making a definitive diagnosis, CECT has proven to be useful for deciding on the treatment approach. In the present case, multiple hair masses were observed in the stomach and small intestine, so gastrotomy alone was considered to insufficient. Therefore, we decided to perform gastrotomy and jejunostomy for the complete removal of the hair masses in the present case. CECT allowed us to make a definitive diagnosis of Rapunzel syndrome and to detect the location of the hair masses simultaneously.

Recently, minimally invasive techniques have been employed to remove gastric trichobezoar. In 1998, a case of successful laparoscopic removal of trichobezoar was reported. ${ }^{4}$ Although a laparoscopic approach can achieve a better cosmetic outcome with lower invasiveness then other approaches, this technique takes a longer and is more complex. However, the trichobezoar extends to multiple locations of the gastrointestinal tract in Rapunzel syndrome. Surgeons should, therefore, examine the entire gastrointestinal tract to achieve complete elimination of trichobezoars and avoid secondary intestinal obstruction due to satellites. ${ }^{5}$ In the present case, a laparoscopic approach was considered to be inappropriate, as CECT revealed gastric and multiple intestinal hair masses and remarkable small bowel dilatation. Moreover, intestinal wall weakness was suspected when we took into account the period from the onset of bowel obstruction to the surgery. Therefore, radical laparotomy is considered to be reasonable and feasible for the treatment of Rapunzel syndrome.

In the present case, two factors were involved in the development of Rapunzel syndrome. The first factor was the absence of subjective symptoms. The patient consistently denied swallowing foreign bodies even after the definitive diagnosis of Rapunzel syndrome was made. In addition, the patient was embarrassed when she realized that the cause of the small bowel obstruction was swallowed hairballs. An analysis of 1,400 trichotillomania cases revealed that trichotillomania consisted of two different pulling styles: automatic and focused type. In focused type cases, the patients have an obvious desire to perform trichotillomania and trichophagia. In contrast, an automatic type cases, the behavior is not consciously recognized by the patient, as in the present case. Given that the automatic type is typically found predominantly in young children, it is difficult to detect pediatric trichotillomania at an early stage. ${ }^{6}$

The second factor was the inappropriate medical care that the patient initially received for her trichotillomania. The patient had not undergone any detailed clinical investigation or follow-up care since she was first diagnosed with trichotillomania. In a previous report of 68 trichotillomania patients, 19 $(27.9 \%)$ were reported to have lifetime trichophagia. ${ }^{7}$ Trichobezoar formation and Rapunzel syndrome are the most severe physical impairment resulting from trichophagia and can occur in patients of any age with trichotillomania. Rapunzel syndrome has been documented in females as young as 2.5 years old. ${ }^{8}$ The management of pediatric cases of trichotillomania requires special attention due to the high rate of association with trichopha- 
gia and the severity of trichobezoars and Rapunzel syndrome.

\section{CONCLUSION}

In conclusion, CECT is useful for making a definitive diagnosis of Rapunzel syndrome and determining the surgical approach. Radical laparotomy is considered to be reasonable and feasible in cases of Rapunzel syndrome that manifests as acute abdominal symptoms.

\section{CONFLICTS OF INTEREST}

All authors have no conflicts of interest.

\section{CONSENT FOR PUBLICATION}

Written informed consent was obtained from the patient and the parents for publication of this case report.

\section{FUNDING}

This study was not funded externally.

\section{AUTHORS' CONTRIBUTIONS}

All authors performed the operation. NH wrote the manuscript. All authors read the manuscript and approved the final manuscript.

\section{REFERENCES}

1. Vaughan ED Jr, Sawyers JL, Scott HW Jr. The Rapunzel syndrome. An unusual complication of intestinal bezoar. Surgery. 1968; 63(2): 339-343. doi: 10.1016/0022-3468(68)901
$55-3$

2. Altintoprak F, Degirmenci B, Dikicier E, et al. CT findings of patients with small bowel obstruction due to bezoar: A descriptive study. Scientific World Journal. 2013; 2013: 298392. doi: $10.1155 / 2013 / 298392$

3. Zissin R, Osadchy A, Gutman V, Rathaus V, Shapiro-Feinberg M , Gayer G. CT findings in patients with small bowel obstruction due to phytobezoar. Emerg Radiol. 2004; 10(4): 197-200. doi: 10.1007/s10140-003-0297-0

4. Nirasawa Y, Mori T, Ito Y, Tanaka H, Seki N, Atomi Y. Laparoscopic removal of a large gastric trichobezoar. $J$ Pediatr Surg. 1998; 33(4): 663-665. doi: 10.1016/S0022-3468(98)90 $342-6$

5. Al-Janabi IS, Al-Sharbaty MA, Al-Sharbati MM, Al-Sharifi LA, Ouhtit A. Unusual trichobezoar of the stomach and the intestine: A case report. J Med Case Rep. 2014; 8: 79. doi: 10.1186/1752-1947-8-79

6. Flessner CA, Woods DW, Franklin ME, Keuthen NJ, Piacentini J. Cross-sectional study of women with trichotillomania: A preliminary examination of pulling styles, severity, phenomenology, and functional impact. Child Psychiatry Hum Dev. 2009; 40(1): 153-167. doi: 10.1007/s10578-008-0118-5

7. Grant JE, Odlaug BL. Clinical characteristics of trichotillomania with trichophagia. Compr Psychiatry. 2008; 49 (6): 579584. doi: 10.1016/j.comppsych.2008.05.002

8. Middleton E, Macksey LF, Phillips JD. Rapunzel syndrome in a pediatric patient: A case report. AANA J. 2012; 80(2): 115-119. 